\title{
In vitro and in vivo studies of antitumor effects of the recombinant immunotoxin MSH-PE38KDEL on melanoma
}

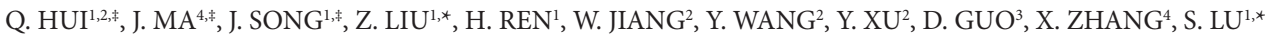

${ }^{1}$ Key Laboratory of Zoonosis Research, Ministry of Education, Institute of Zoonosis, College of Veterinary Medicine, Jilin University, Changchun, Jilin 130062, China; ${ }^{2}$ Changchun Institute of Biological Products Co., Ltd., Jilin 130062, China; ${ }^{3}$ College of Food, Heilongjiang Bayi Agricultural University, Daqing, Heilongjiang 163319, China; ${ }^{4}$ Department of Immunology, Norman Bethune Medical School, Jilin University, Changchun, Jilin 130021, China

*Correspondence: zsliu1959@163.com,lushiying1129@163.com

${ }^{*}$ Contributed equally to this work.

Received August 6, 2013 / Accepted November 12, 2013

\begin{abstract}
MSH-PE38KDEL is a chimeric molecule composed of MSH, and fused to a truncated mutant form of Pseudomonas exotoxin (PE38KDEL). Our study aims to evaluate the specific cytotoxicity of recombinant immunotoxin MSH-PE38KDEL on melanoma cells A875 and B16 in vitro, as well as its inhibition of metastatic melanoma in vivo. MSH-PE38KDEL was expressed in Escherichia coli, and greater than $90 \%$ purity was obtained. The purified MSH-PE38KDEL was found to be selectively cytotoxic to MSH receptor-positive melanoma cells in vitro. The specific cytotoxicity of recombinant MSH-PE38KDEL to A875 and B16 was over $85 \%$ by cell viability assay; however, MSH-PE38KDEL had no cytotoxicity to the human 2BS cells. The antitumor activity of MSH-PE38KDEL was evaluated in mice with induced melanoma through intra-tumor or intravenous administration. The results showed that $90 \%$ melanoma growths were inhibited, and $40 \%$ of the tumors were disappeared completely. Histopathology results showed MSH-PE38KDEL can effectively inhibit intrahepatic metastasis. In conclusion, MSH-PE38KDEL had cytotoxic effects on MSH receptor-positive melanoma cells, and causes significant tumor growth inhibition. These results support a possible new approach for the treatment of melanoma.
\end{abstract}

Key words: recombinant immunotoxins, MSH-PE38KDEL, melanoma, antitumor

Melanoma is one of the malignant tumors with the fastest growing incidence at approximately $3 \%$ to $5 \%$ growth annually [1-3]. Although high doses of interferon- $\alpha$ and interleukin-2 have some therapeutic effects in patients with melanoma [47], the most effective method for the treatment of metastatic melanoma has not been found. A recombinant immunotoxin has been proposed as an effective (adjuvant) treatment with high specificity for melanoma. Cytotoxic melanophore-stimulating hormone $(\alpha-\mathrm{MSH})$ is a neuroendocrine hormone with a physiological role in promoting melanocyte proliferation and differentiation and melanin formation [8-9]. Its receptors are widely present on the surface of many tumor cells, in particu-

Abbreviations: PE, Pseudomonas exotoxin; $\alpha-\mathrm{MSH}$, Melanophorestimulating hormone; IPTG, isopropyl- $\beta$-D-1-thiogalactopyranoside; $E$. coli, Escherichia coli; MTS, 3-(4,5-dimethylthiazol-2-yl)-5-(3-carboxymethoxyphenyl)-2-(4-sulfophenyl)-2H-tetrazolium lar, the surface of malignant melanoma. Studies have shown fewer than $100 \mathrm{MSH}$ receptor sites on normal human cells or epidermal melanocytes, but approximately 900-5,700 MSH receptors on the human melanoma cell surface [10-12]. $\alpha-\mathrm{MSH}$ has high affinity for its receptor[13] , and therefore might be used as a specific targeting vector.

Recombinant immunotoxins are chimeric proteins in which a truncated toxin that serves as the cytotoxic moiety is fused to an Fv portion of an antibody that serves as the targeting moiety. The pseudomonas exotoxin (PE) shows high toxicity and its cytotoxicity mechanism has been elucidated; it appears to be an ideal preparation of immunotoxin [14-15]. The structure of mutated and truncated forms of PE is PE38KDEL. The $\mathrm{N}$-terminal domain Ia (aa1-252) of PE has an antiparallel $\beta$ structure and is responsible for cell recognition. In PE38KDEL, domain Ia has removed from PE. Therefore, PE38KDEL nonspecific binding to the cells is reduced. And PE38KDEL 
has removed amino acids (365-380) from domain Ib of PE to reduce immunogenicity and increasing penetration [16]. PE38KDEL has an altered carboxyl terminus from the REDLK to the KDEL sequence, which binds with higher affinity to the KDEL receptor and results in increased cytotoxicity [17-18]. In addition, the disadvantages of $\mathrm{PE}$ in nonspecific binding and low penetration have been reduced in PE38KDEL. As "warheads," it has the characteristics of low molecular weight, high toxicity, cell-killing effects, and specific binding; therefore the PE38KDEL is widely used in creating recombinant immunotoxins [19].

In this study, we constructed a novel recombinant immunotoxin MSH-PE38KDEL. We investigated whether MSH-PE38KDEL had specific cytotoxicity to the melanoma cells A875 and B16 in vitro and its inhibition of metastatic melanoma in vivo. Based on our results, we propose the immunotoxin MSH-PE38KDEL as an effective treatment for melanoma.

\section{Materials and methods}

Plasmids and cells. The pET-28a vector $(+)$ was purchased from Novagen, U.S.A; the E. coli DH5 $\alpha$ and host strain Rosetta-gami ${ }^{\mathrm{TM}} 2$ (DE3) were obtained from TaKaRa (Dalian) Co., Ltd, Japan. The human melanoma A875 cells, nasopharyngeal cancer CNE cells, mouse melanoma high transfer B16-F10 cell line ( B16 cells), and the breast cancer MCF cell line were purchased from the Cell Bank of the Chinese Academy of Sciences Type Culture Collection Committee, Shanghai, China. The human embryonic lung diploid fibroblast cell line (2BS cells) was purchased from the Changchun Institute of Biological Products, Changchun, China.

Experimental animals. The specific-pathogen-free (SPF) $\mathrm{NIH} /$ nu nude mice (6- to 8-week-old females, weighing 18-22 g) were kindly provided by Changchun Institute of Biological Products Co., Ltd, Changchun, China. A maximum of four mice were housed per cage. Food and tap water were available ad libitum. The animal housing facilities were maintained on a 12-h light/dark cycle, with constant temperature (20 24 ${ }^{\circ} \mathrm{C}$ ) and $50 \%$ humidity. All animal experiments were done in accordance with the Institutional Animal Care and Use Committee's guidelines at the Jilin University.

Design and synthesis of the MSH-PE38KDEL gene. The target toxin MSH-PE38KDEL is a fusion protein that was constructed by connecting the MSH gene to PE38KDEL with the flexible Linker SGGGGS (synthesized by TaKaRa Biotechnology, Dalian Co., Ltd.). The MSH-PE38KDEL gene sequence was encoded using $E$. coli-preferred codons and was sequenced by Jcat software [20]. The complete gene sequences with restriction enzyme sites $\mathrm{XbaI}$ and $\mathrm{BamHI}$ were synthesized, cloned into the T7 vector, and then transformed into the E. coli DH5a. strains by the Shanghai Sangon Biotechnology Company.

Induced expression and purification of MSH-PE38KDEL. The gene fragment encoding MSH-PE38KDEL was inserted between the XbaI and BamHI sites of the expression vector pET28a (+) plasmid (Novagen). The expression vector pET28 a (+)-MSH-PE38KDEL was transferred into Rosetta-gamiTM2 (DE3). The plasmid-bearing Rosetta-gamiTM2 (DE3) was then inoculated into Amp-resistant culture medium and allowed to multiply, with shaking speed at $160-170 \mathrm{rpm}$ at $37^{\circ} \mathrm{C}$, until reaching the logarithmic growth phase. Then, isopropylthio$\beta$-galactoside was added at a final concentration of $1 \mathrm{mmol} / \mathrm{l}$ and the culture was continuously shaken for $6 \mathrm{~h}$ at $180 \mathrm{rpm}$ at $37^{\circ} \mathrm{C}$. Bacteria were collected, MSH-PE38KDEL protein as analyzed by gel imaging analysis system, and the supernatant and pellet were separated by centrifugation after ultrasonic disruption at $300 \mathrm{~W}$. The supernatant and pellet were both analyzed by sodium dodecyl sulfate polyacrylamide gel electrophoresis (SDS-PAGE) and western blotting. The expressed product was purified from the supernatant, because the protein is soluble in E. coli supernatant. After ultrasonic treatment, the solution was precipitated through $40 \%$ ammonium sulfate, and suspended in $10 \mathrm{mmol}$ TE buffer. The protein was purified through three stages of chromatography in hydrophobic (Phenyl FF [high sub]) chromatography, diethylaminoethyl (DEAE) Sepharose Fast Flow ion-exchange chromatography, and Sephacryl (S-200) High Resolution molecular sieve chromatography. The protein sample was analyzed at each stage by $12 \%$ SDS-PAGE.

In vitro cytotoxicity activity of MSH-PE38KDEL. The in vitro specific cytotoxicity of the recombinant immunotoxin MSH-PE38KDEL was studied using A875 and B16 cells which express the MSH receptors, and CNE, MCF, 2BS cells which do not express the MSH receptors. Each cell type was cultured using RPMI-1640 complete culture solution with $15 \%$ fetal bovine serum at $37^{\circ} \mathrm{C}, 5 \% \mathrm{CO}_{2}$ At the logarithmic growth phase, cells were diluted with RPMI- 1640 culture medium and counted, and the concentration was adjusted to about $1 \times 10^{5} \mathrm{cells} / \mathrm{ml}$. The cell suspension was added to a 96 -well cell culture plate $(100 \mu \mathrm{l} /$ well $)$ and cultured at a $37^{\circ} \mathrm{C}, 5 \% \mathrm{CO}_{2}$. The MSH-PE38KDEL protein was diluted with phosphate buffer at the concentrations of 5 $\mathrm{ng} / \mathrm{ml}, 25 \mathrm{ng} / \mathrm{ml}, 100 \mathrm{ng} / \mathrm{ml}, 200 \mathrm{ng} / \mathrm{ml}, 400 \mathrm{ng} / \mathrm{ml}, 600 \mathrm{ng} / \mathrm{ml}$, $800 \mathrm{ng} / \mathrm{ml}$ and $1000 \mathrm{ng} / \mathrm{ml} .100 \mu \mathrm{L} /$ well of MSH-PE38KDEL with different doses or $0.9 \% \mathrm{NaCl}$ (negative control) were added, separately. The plates were then cultured at a $37^{\circ} \mathrm{C}, 5 \%$ $\mathrm{CO}_{2}$. The state of cell growth was checked every day. After 48 hours of incubation, $20 \mu \mathrm{l} /$ well MTS/PMS was added. The MTS (3-(4,5-dimethylthiazol-2-yl)-5-(3-carboxymethoxyphenyl)-2(4-sulfophenyl)-2H-tetrazolium)assay is often described as a 'one-step' MTT assay, which offers the convenience of adding the reagent straight to the cell culture without the intermittent steps required in the MTT assay. These assays measure cellular metabolic activity and reflect the number of viable cells present. Then $200 \mu \mathrm{l} /$ well of dimethyl sulfoxide was added. The plates were shaken for $10 \mathrm{~min}$ and were incubated for 3 additional hours. Then the plates were read at $490 \mathrm{~nm}$ using a microreader. The killing rate of MSH-PE38KDEL at each concentration was calculated:

(1)Cell viability (\%) = experimental OD/control OD [21] 
The inhibition of murine melanoma by MSH-PE38KDEL. Ten mice were injected with saline, and other thirty NIH/nu nude mice were injected $(0.2 \mathrm{ml} /$ mouse $)$ subcutaneously at the axillae with $\mathrm{B} 16$ cells at concentration of $1 \times 10^{7} / \mathrm{ml}$. The nodules were measured with a $1 / 50 \mathrm{~mm}$ vernier caliper daily. The tumor-bearing mouse model was ready for analysis when the longest diameter reached 4-6 $\mathrm{mm}$. Thirty mice were divided into three groups for testing the anti-tumor activity of MSH-PE38KDEL:

Negative control group: 10 mice without tumor, fed for 10 days as other groups, and injected intravenously with $0.5 \mathrm{ml}$ saline, daily.

Positive control group: 10 tumor-bearing mice, fed for 10 days as other groups, injected intravenously with $0.5 \mathrm{ml}$ saline, daily.

Intra-tumor immunotoxin administration group: 10 tumor-bearing mice, fed for 10 days as other groups, injected $(0.25 \mathrm{ml} /$ mouse $)$ intra-tumor with $1.1 \mathrm{mg} / \mathrm{ml} \mathrm{MSH}$ PE38KDEL daily for consecutive 10 days.

Intravenous immunotoxin administration group: 10 tumorbearing mice, fed for 10 days as other groups, injected $(0.25$ $\mathrm{ml} /$ mouse) intravenously with $1.1 \mathrm{mg} / \mathrm{ml} \mathrm{MSH}$-PE38KDEL daily for consecutive 10 days.

The nodules were measured with a vernier caliper daily and the following formula was used to calculate the tumor volume:

(1) Tumor volume $=a^{2} \times b \times \pi / 6$ ( $a$ is the shortest diameter, $b$ is the longest diameter).

The mice were sacrificed after 10 days of treatment. The inhibitory rate was calculated based on the mean tumor volumes last measured prior to sacrifice.
(2) Tumor suppression rate (\%) $=[$ (tumor volume of positive control group - experimental group tumor volume)] / tumor volume of positive control group] $\times 100 \%$.

(3) Tumor disappearing rate $(\%)=$ (number of tumor disappearing mice) /10

Histopathologic and ultrastructure electron micrograph analyses. To determine the tumor growth and metastasis, the pathological changes of the tumor sides of heart, liver, spleen, lung, kidney, and intestine were observed by light microscopy and transmission electron microscopy.

Statistical analysis. The data are presented as mean $( \pm \mathrm{SD})$ for each group, unless indicated otherwise. The statistical analysis of data was performed by $t$-test and $F$-test analysis using the software package SAS version 9.2 (Statistical Analysis System, SAS Institute Inc., Cary, NC, USA). A $P$ value of 0.05 was considered statistically significant.

\section{Results}

Expression and purification of MSH-PE38KDEL. The MSH-PE38KDEL fusion protein was sequenced and found to be correct by Dnaman software analysis. The Mr arm of the protein was about $40 \mathrm{kDa}$ by SDS-PAGE (Figure 1A), corresponding to theoretical calculations. The MSH-PE38KDEL protein constituted $10 \%$ of the total bacterial protein as analyzed by gel imaging analysis system. Western blotting of supernatant and precipitate showed that corresponding mouse anti-PE38-specific band appeared in the supernatant (Figure 1B), and proved the fusion protein was soluble. The
A

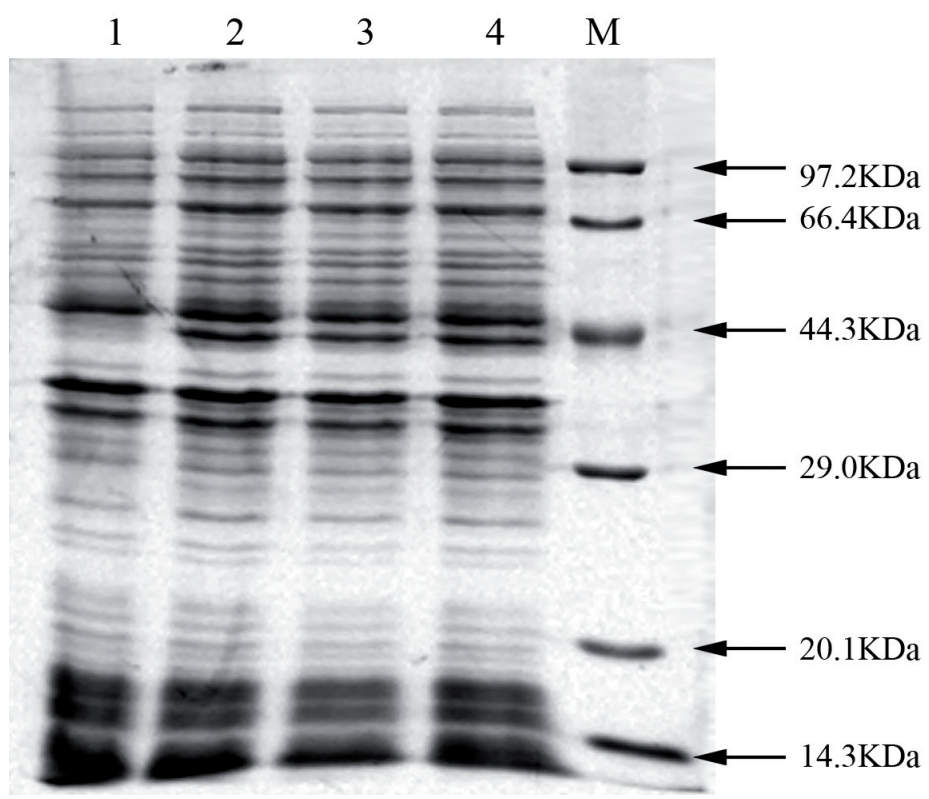

B

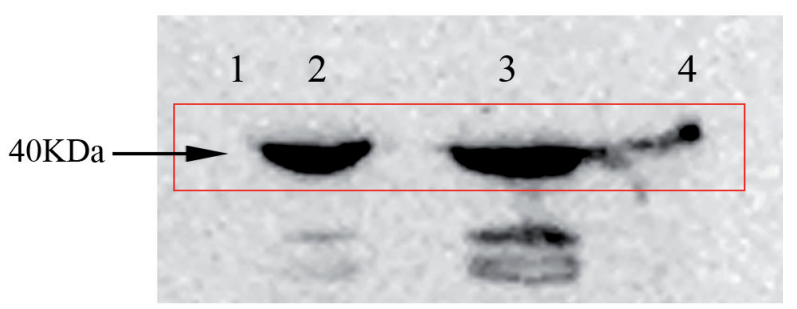

Figure 1. SDS-PAGE analysis of pET28a (+) -MSH-PE38KDEL (A). M: low molecular weight protein marker; Lane 1: pET28a (+) induction in Rosetta; Lane 2, 3, 4: pET28 a(+)-MSH-PE38KDEL induction in Rosetta. Western blot assay of MSH-PE38KDEL after ultrasound (B). Lane 1: pET28a (+) induction in Rosetta; Lane 2: pET28 a (+)-MSH-PE38KDEL induction in Rosetta; Lane 3: Supernatant after ultrasound; Lane 4: Settling after ultrasound. 
MSH-PE38KDEL fusion protein with purity greater than $90 \%$ could be obtained by serial purification by Phenyl FF (high sub) hydrophobic chromatography, DEAE Sepharose Fast Flow ion exchange chromatography, and Sephacryl (S-200) High Resolution molecular sieve chromatography (Figure 2A). SDS-PAGE analysis validated this purification (Figure 2B).

The specific toxicity of MSH-PE38KDEL in tumor cells. The MSH-PE38KDEL had significant dose dependent killing effects on A875 and B16 cells within 48 hours and had no killing effects on CNE, MCF, or 2BS cells. At the dose of 600 $\mathrm{ng} / \mathrm{ml}$, the MSH-PE38KDEL had the highest killing effects on A875 cells and B16 cells and the survival rates of these two cell types were $6.9 \%$ and $10.9 \%$, respectively (Figure $3 \mathrm{~A}$ ). Microscopy observation also confirmed that $600 \mathrm{ng} / \mathrm{ml} \mathrm{MSH-}$ PE38KDEL significantly reduced cell viabilities in A875 cells and B16 cells (Figure 3B).

The antitumor effects of recombinant immunotoxin MSH-PE38KDEL on tumor-bearing mice. To determine MSH-PE38KDEL's antitumor effects in vivo, B16 cells were transplanted to mice using the method described in "Materials and Methods". On the fifth day, the subcutaneous melanoma was visible; on the eighth day the tumor diameter was up to $1.34 \mathrm{~cm}$ (Figure 4A); on the 10th day tumor diameter was up to $1.68 \mathrm{~cm}$ (Figure $4 \mathrm{~B}$ ). The adequacy of the animal model created was thus confirmed.

The mice were treated for 10 days. The melanoma tumors of the positive control group grew rapidly, while the tumors of mice in intra-tumor administration and intravenous admin- istration groups grew slowly and contractured gradually. The total volume of tumors were quantified in the positive control, intra-tumor and intravenous administration groups (Figure $4 \mathrm{C}$ ). When the average tumor volume in the same group of the different days were compared, there were a significant difference in the positive control group $(F=87.27, P<0.01)$, intra-tumor group $(F=50.49, P<0.01)$, and intravenous group $(F=53.93, P<0.01)$.

The mean tumor volume of each group on the same day was compared, showing there was no significant difference between groups on day $1(F=0.66, P>0.05)$ and day $2(F=1.36$, $P>0.05)$. However, there were significant differences on day 3 $(F=39.8, P<0.01)$, day $4(F=100.7, P<0.01)$, day5 $(F=233.7$, $P<0.01)$, day6 $(F=343.7, P<0.01)$, day $7(F=185.8, P<0.01)$, day $8(F=242.3, P<0.01)$, day $9(F=349.8, P<0.01)$, and day $10(F=503.7, P<0.01)$. The suppression rate and disappearing rate of the treated groups after 10 days of administration are shown in Table 1.

The tumors of three mice disappeared in the intra-tumor group after 10 days of administration. The tumors of four mice disappeared in the intravenous group after 10 days of administration. The gross anatomy of tumor growth in tumorbearing mice was also determined. In positive control group mice, there were obvious tumor nodule (Figure 4D), however, the tumor integument is incomplete in intra-tumor injection group mice (Figure $4 \mathrm{E}$ ) and only observing melanin imprint in i.v. injection group mice (Figure $4 \mathrm{~F}$ ). These results suggest that recombinant immunotoxin MSH-PE38KDEL has antitumor effects on tumor-bearing mice.
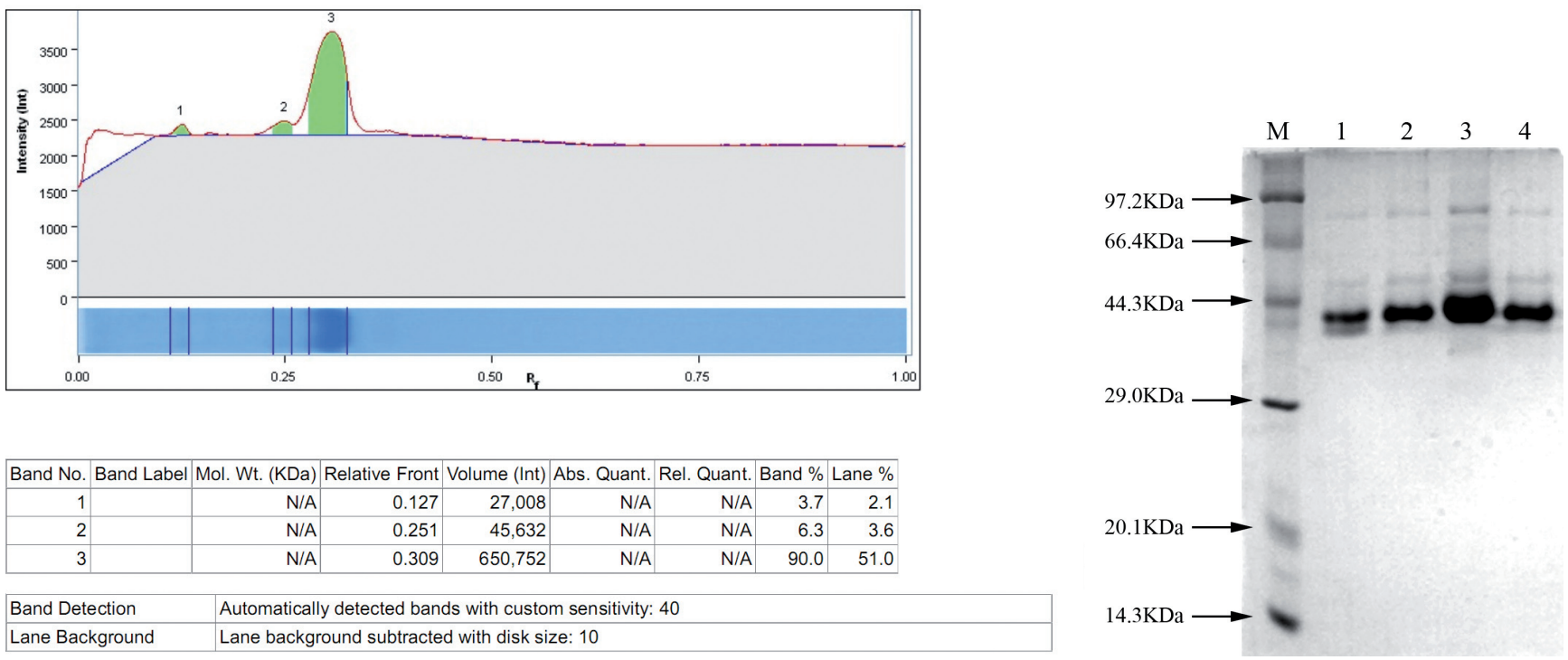

\begin{tabular}{|c|c|c|c|c|c|c|c|c|}
\hline \multirow{2}{*}{$\begin{array}{r}\text { Band No. } \\
1\end{array}$} & \multicolumn{2}{|c|}{. Band Label Mol. Wt. (KDa) } & \multicolumn{2}{|c|}{ Relative Front Volume (Int) } & Abs. Quant. & \multicolumn{3}{|c|}{ Rel. Quant. Band \% Lane \% } \\
\hline & & $\mathrm{N} / \mathrm{A}$ & 0.127 & 27,008 & $\mathrm{~N} / \mathrm{A}$ & $\mathrm{N} / \mathrm{A}$ & 3.7 & 2.1 \\
\hline 2 & & $\mathrm{~N} / \mathrm{A}$ & 0.251 & 45,632 & N/A & N/A & 6.3 & 3.6 \\
\hline 3 & & N/A & 0.309 & 650,752 & N/A & N/A & 90.0 & 51.0 \\
\hline Band Dete & tection & Automatically & ed banc & ds with custon & m sensitivity: & & & \\
\hline Lane Back & ckground & Lane backgro & round subtracte & d with disk siz & ze: 10 & & & \\
\hline
\end{tabular}

Figure 2. SDS-PAGE assay of MSH-PE38KDEL after S-200 molecular sieve chromatography purification. Thin layer scanning of SDS-PAGE gel showed that the target protein's percent is $\mathbf{9 0 . 0} \%$. (A) SDS-PAGE assay of MSH-PE38KDEL. (B) M: low molecular weight protein marker. Lane 1: before peak protein 1. Lane 2: before peak protein 2; Lane 3: MSH-PE38KDEL with S-200; Lane 4: peak tail protein. 
A

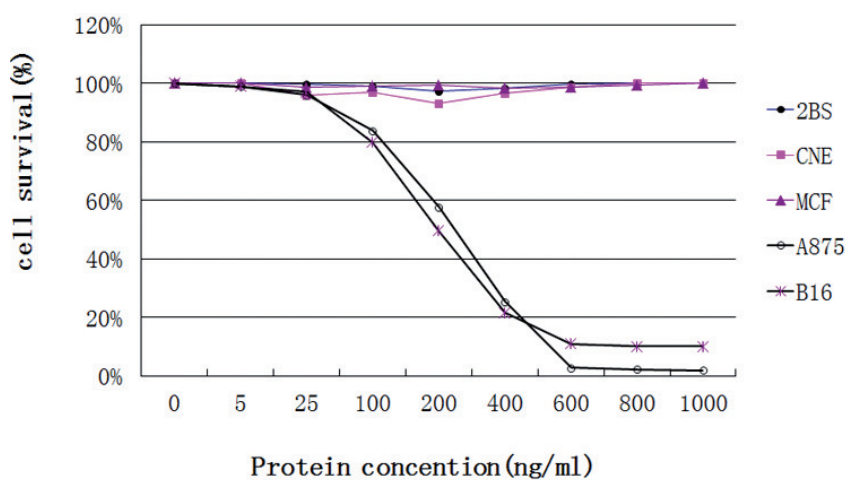

B

$\mathrm{B} 16$
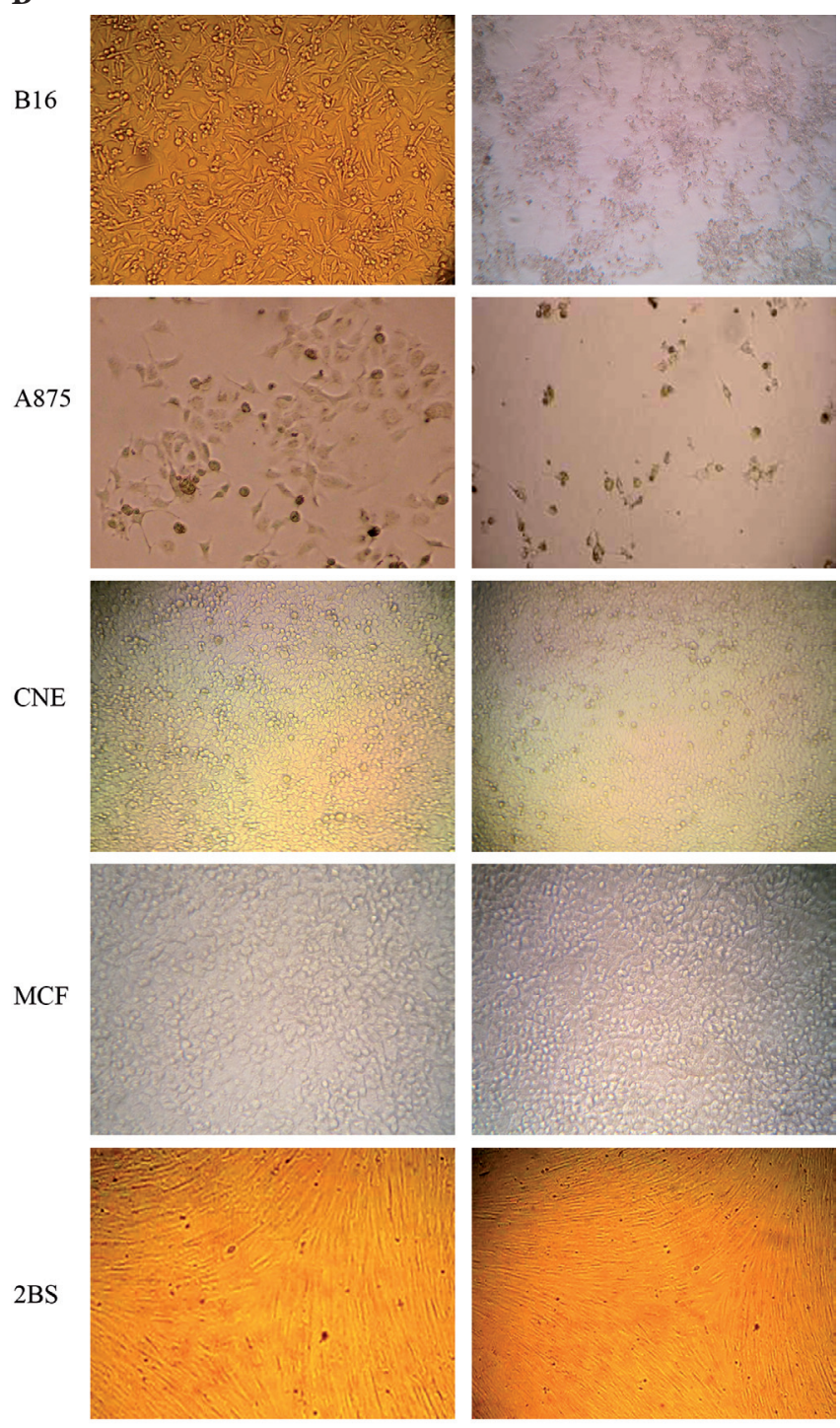

Control

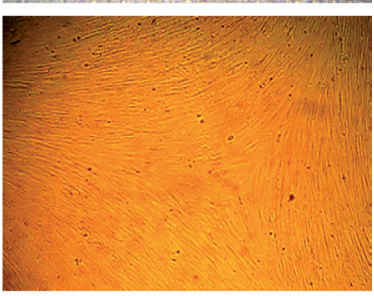

MSH-PE38KDEL (600ng/ml)

Figure 3. (A) Cytotoxic activity of MSH-PE38KDEL in B16, A875, CNE, MCF and 2BS cells by MTS assay. (B) Light micrographs of B16, A875, CNE, $\mathrm{MCF}$ and 2BS cells treated with $600 \mathrm{ng} / \mathrm{ml}$ MSH-PE38KDEL for $48 \mathrm{~h}$.

Table 1. Tumor suppression and Disappearing rate of the treated groups (\%)

\begin{tabular}{lccc}
\hline Group & $\mathrm{n}$ & Suppression rate & Disappearing rate \\
\hline Intra-tumor injection & 10 & $92.3 \%$ & $30 \%$ \\
i.v. injection & 10 & $95.6 \%$ & $40 \%$ \\
\hline
\end{tabular}

Intra-tumor or intravenous administration inhibits tumor cell metastasis in the mice liver. The cell morphology and ultrastructure of spleen, lung, kidney, and duodenum of the positive control group, the intra-tumor group, and intravenous group were comparable to the negative control group under light and transmission electron microscopy observation (data not shown). However, melanoma metastasis could be seen in the livers of positive control group with observation of cell atypia, deeply stained nuclei, and mitotic figures using low and high magnifications (Figure 5A and 5B, black arrow).

Under transmission electron microscopy observation, there were no abnormalities in the mice livers of the negative control, intra-tumor or intravenous administration group (Figure 6A, $\mathrm{C}$, and $\mathrm{D}$ ). However, the liver ultrastructure of the positive control group changed significantly as compared with the negative control group. The transmission electron microscopy showed that hepatocyte nucleolus contraction, nucleolus membrane lysis (Arrow 1), rough endoplasmic reticulum structure (Arrow 2), increased fat lysis and vacuolation (Arrow 3 ) in the positive group (Figure 6B).

\section{Discussion}

The aim of the present study was to evaluate the MSHPE38KDEL's antitumor activity in vitro and in vivo. Based on the toxicity mechanism of PE and the guiding role of $\alpha$ MSH [12-15], we constructed the recombinant immunotoxin MSH-PE38KDEL for the treatment of malignant melanoma. The recombinant immunotoxin was prepared based on the integration of toxin molecules and guide molecules through recombinant technology, expression, and purification. It showed application prospects in anti-cancer therapy and immune regulation [22].

The target toxin MSH-PE38KDEL is a fusion protein that was constructed by connecting

MSH gene to PE38KDEL with the flexible Linker SGGGGS. The arm of the protein was about $40 \mathrm{kDa}$ by SDS-PAGE, which corresponded to the theoretical calculations. The recombinant expression vector pET28a (+)-MSH-PE38KDEL was constructed by linking the MSH-PE38KDEL gene to the prokaryotic expression vector pET28a. And the recombinant immunotoxin was expressed in Rosetta-gamiTM2 (DE3). The MSH-PE38KDEL fusion protein was $10 \%$ of the total bacterial protein analyzed by gel imaging analysis system. The western blot of supernatant and precipitate showed that corresponding mouse anti-PE38 specific band appeared in the supernatant, and proved the fusion protein is a soluble expression. The SDSPAGE analysis showed the MSH-PE38KDEL fusion protein 
A

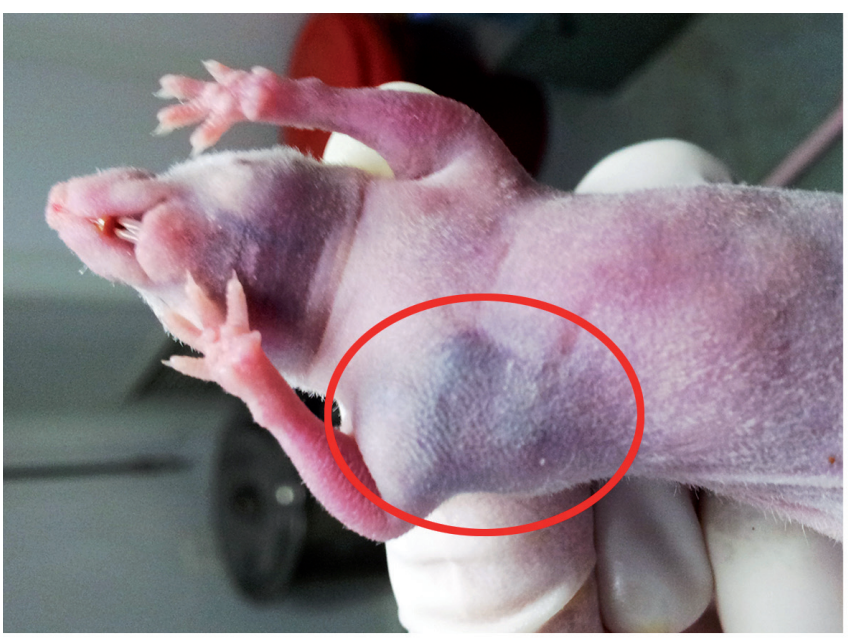

C

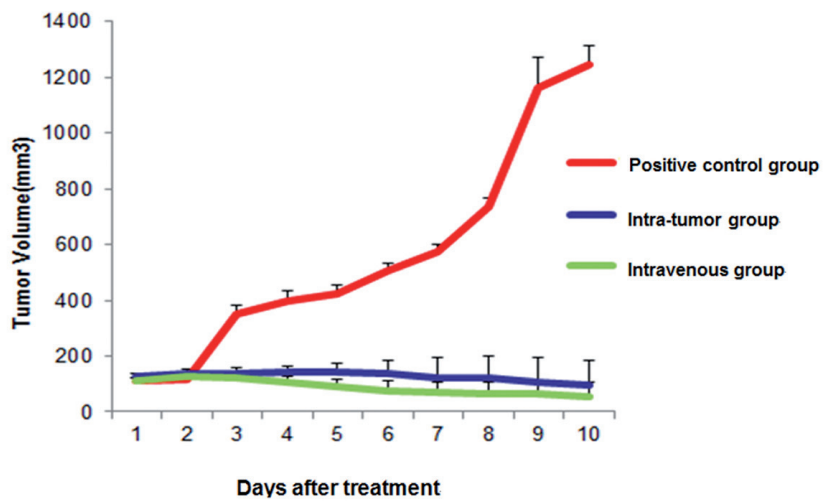

E

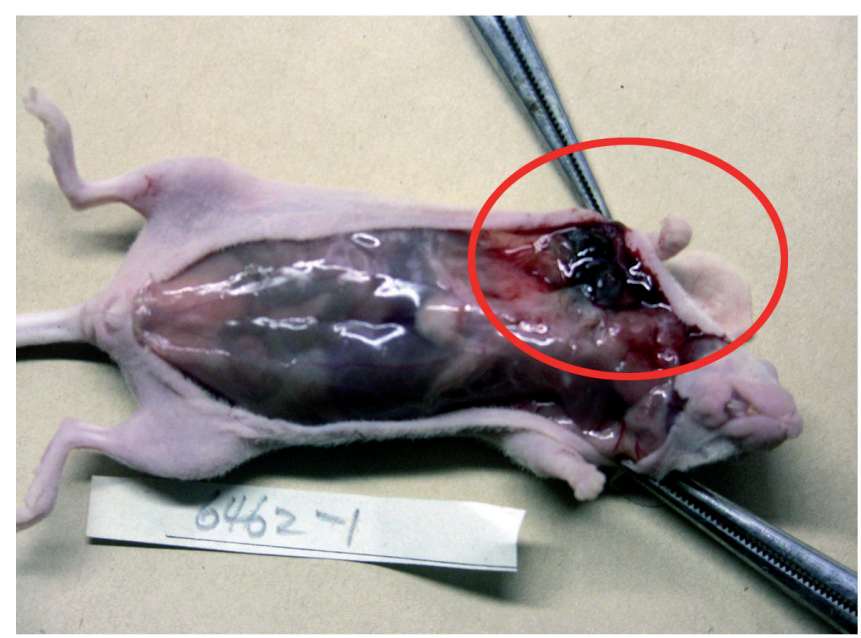

B

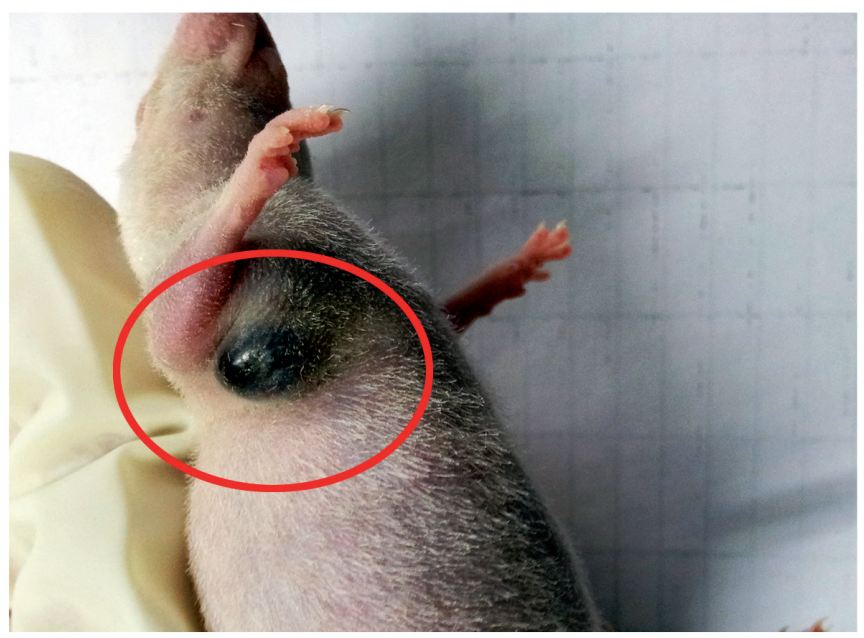

D

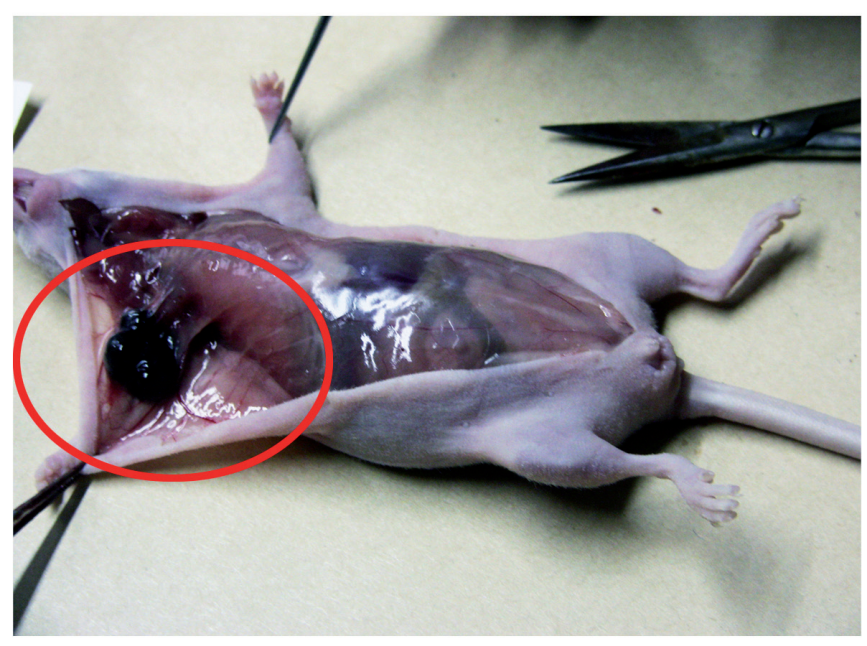

F

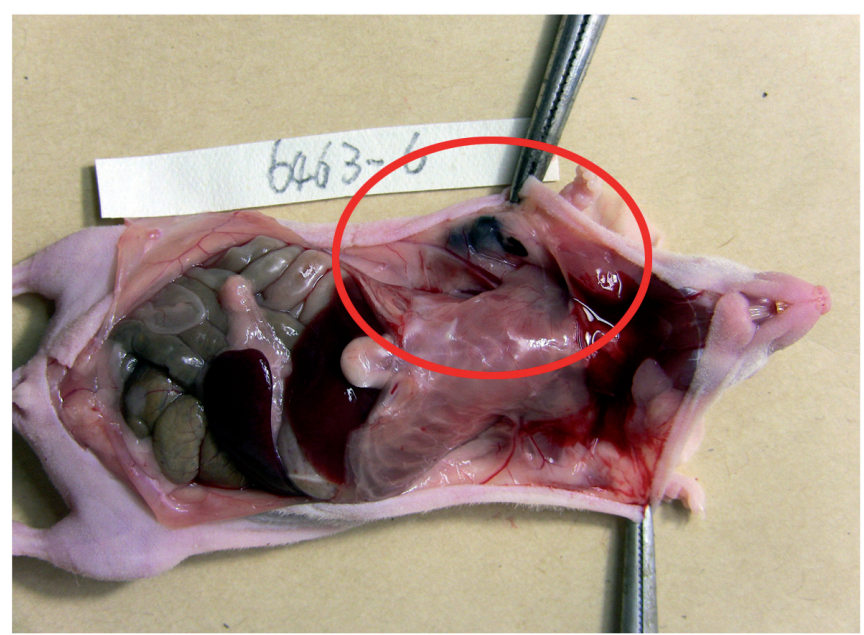

Figure 4. Tumor-bearing mouse model. (A) Mice tumor growth on the 8th day; (B) Mice tumor growth on 10th day. (C) Tumor growth curves of mice in positive control, intra-tumor and intravenous injection groups after treatment.Tumor growth of bearing mice in gross anatomy observation. (D)Tumor nodule of positive control group mice. (E) Tumor integument is incomplete in intra-tumor injection group mice. (F) Only melanin imprint is observed, however there is no nodules in intravenous injection group mice. 

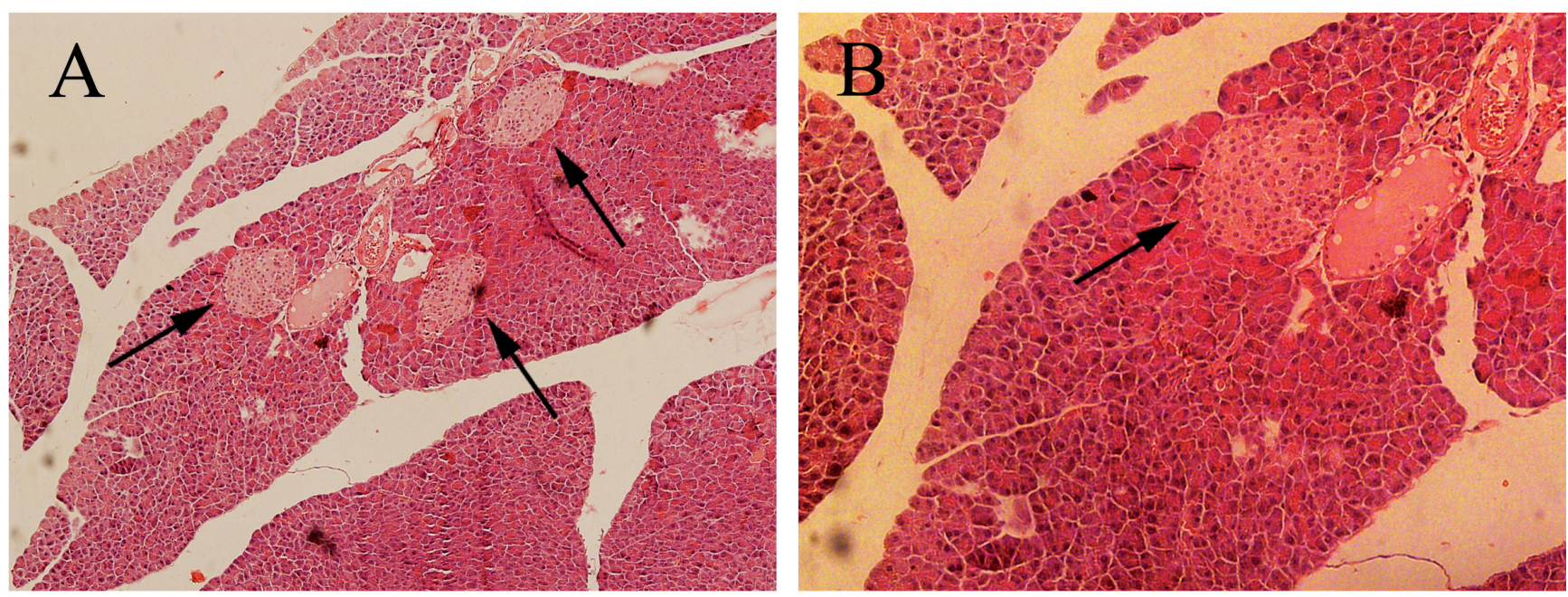

Figure 5. Light micrograph of liver tissue in positive group mice. (A) Light micrograph of liver tissue by low magnification (HE $\times 20)$ in a positive control group mouse. (B) Light micrograph of liver tissue by high magnification $(\mathrm{HE} \times 40)$ in a positive control group mouse.

with purity greater than $90 \%$ could be obtained by Phenyl FF (high sub) hydrophobic chromatography, DEAE Sepharose Fast Flow ion exchange chromatography and Sephaeryl(S200) High Risolution molecular sieve chromatography. These results establish an effective method for creating the immunotoxin protein at high concentration and purity to be used in research applications.

The specific toxicity assay of MSH-PE38KDEL in vitro showed that MSH-PE38KDEL had a significant killing effect on A875 and B16 cells within 48 hours. The resulting survival rates of A875 and B16 cells were very low. The immunotoxin had no killing effect on the CNE cells, MCF cells, and 2BS cells. Studies show that when several PE molecules come into the cell, they cause cell death within 3-5 minutes. In fact, this killing effect was also affected by intracellular conversion efficiency and the efficiency of Furin breaking PE into PE37. The efficiency by Furin is only $5 \%$ to $10 \%$. This process needs a large number of PE molecules into the cell to complete the function of inhibition of protein synthesis [16]. Therefore, the quantity which binds to target cells determines the intracellular conversion efficiency of recombinant immunotoxins. Our in vitro study showed that melanoma A875 and B16 cells have high expression of the MSH receptors, therefore they can bind to sufficient MSH-PE38KDEL thus playing a role in inhibition of protein synthesis in cells and apoptosis activity. We believe that the MSH-PE38KDEL showing no significant cytotoxic effect on the normal human 2BS cells may be due to the small amount expression of MSH receptors in normal cells.

This study also predict that constructed MSH-PE38KDEL binds to MC-1R overexpressed cells specifically in vivo and plays killing effects but not to the human normal cells. This study provide the evidence that the side effects of recombinant immunotoxin will be far less than the chemotherapy drug and further evaluation of side effects will be also needed. MSH recombinant immunotoxin also has specific killing effects on laryngeal cancer Hep-2 cells in in vitro anti-tumor study. The reason may be MCRs presenting on the surface of Hep2 cell. MSH can bind to analogy receptors and plays killing effects [23]. In our study, recombinant immunotoxin MSHPE38KDEL is especially sensitive to the malignant melanoma. Setting up the methods of detecting over-expressed MSH or analogy receptors tumor cells will be the evaluation of the recombinant toxin indications for clinical application.

The melanoma B16-cells tumor-bearing mouse model was successfully established and validated based on the theory that a melanoma metastasis animal model could be constructed by injecting B16 cells into nude mice [22]. The model was used to study the MSH-PE38KDEL's activity in vivo. Our in vivo assay uses two administration routes of melanoma cells-intra-tumor and intravenous-and saline was injected as a control. The results showed that after 10 days of daily injection with a MSH-PE38KDEL concentration $1.1 \mathrm{mg} / \mathrm{ml}(0.25$ $\mathrm{ml} /$ mouse), the tumor growth was inhibited significantly, with an inhibition rate of $>90 \%$. And the tumor disappearance rate using intra-tumor injection was 30\%, and using intravenous injection was $40 \%$. H\&E staining showed that the MSH-PE38KDEL effectively inhibited the intrahepatic metastasis of melanoma B16 cells. The electron microscopy showed that MSH-PE38KDEL inhibited the damaging effects of melanoma B16 cells on the liver cells. These data suggest that MSH-PE38KDEL inhibits tumor growth and metastasis. Commonly used radionuclide and cytotoxic chemotherapy drugs in clinical application do not have the specific killing effects, so it is difficult to avoid the damage of the body's normal cells and the surrounding non-target cells. Therefore, the clinical application has been limited duing to some chemotherapy drugs' toxic side effects. We also observed the liver, kidney and spleen cells ultrastructure using transmission electron mi- 

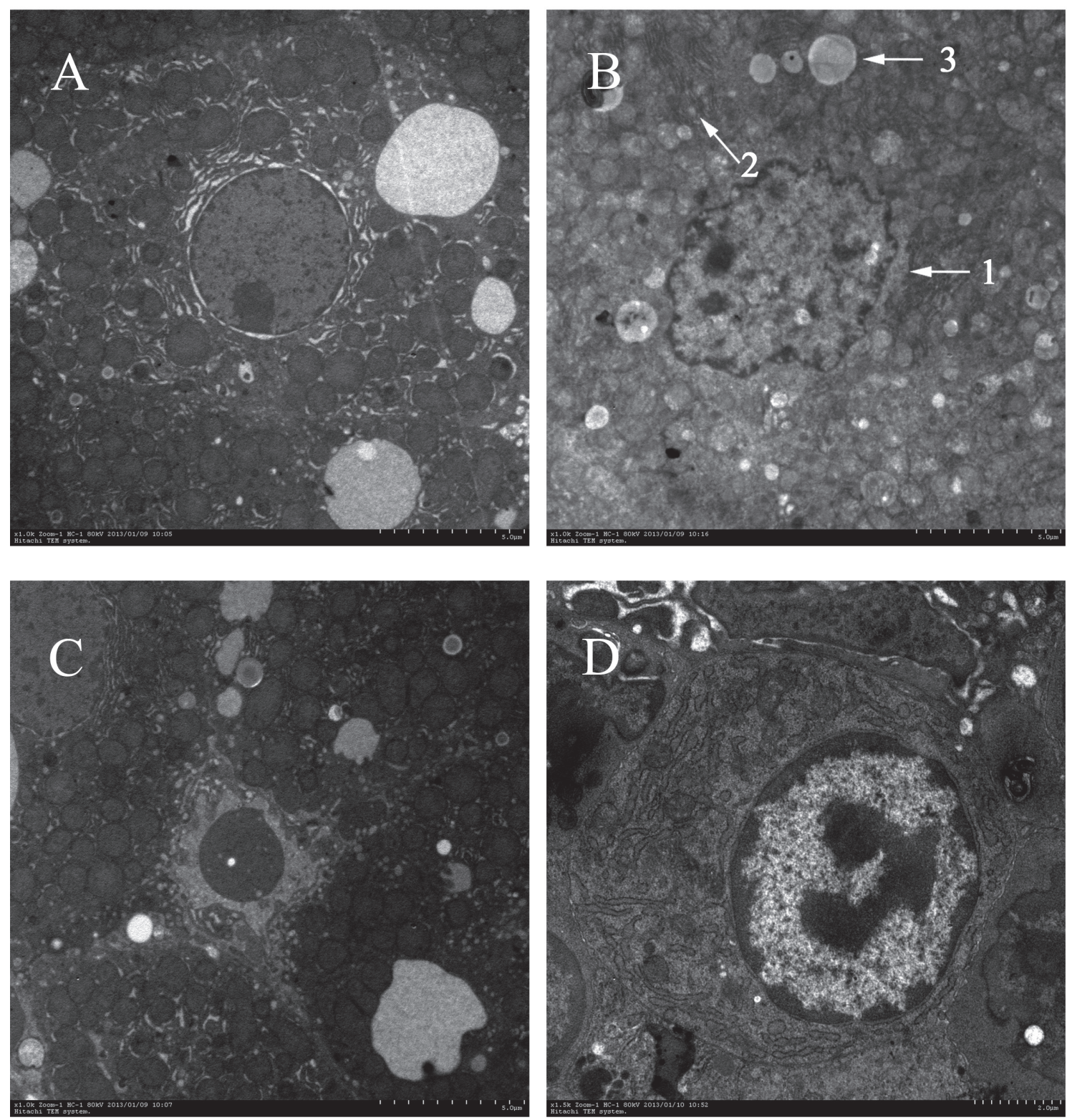

Figure 6. Transmission electron micrographs of liver cells from normal, positive control, intratumor or intravenous administration group mice. (A) Electron micrograph of a liver cell from normal mouse $(\times 1.0 \mathrm{~K})$. (B) Electron micrograph of a liver cell from positive control group mouse. Nucleolus contraction and nucleolus membrane lysis (Arrow 1), rough endoplasmic reticulum structure (Arrow 2), increased fat lysis and vacuolation (Arrow 3). (C) Electron micrograph of a liver cell from intra-tumor administration group mouse $(\times 1.0 \mathrm{~K})$. (D) Electron micrograph of a liver cell from intravenous administration group mouse $(\times 1.5 \mathrm{~K})$.

croscopy. There are no significant cell ultrastructure changes (such as mitochondrial membrane, nuclear membrane) in the intra-tumor or intravenous administration group, confirming the recombinant immunotoxin MSH-PE38KDEL has no toxic side effects to normal human cells, at least the immunotoxin side effects is very little .

In conclusion, evaluation of MSH-PE38KDEL indicated that the recombinant toxin has selective cytotoxicity against MSH expressing melanoma cells in vitro and in vivo. At a dose of $1.1 \mathrm{mg} / \mathrm{ml}(0.25 \mathrm{ml} /$ mouse $)$ for 10 days, MSH-PE38KDEL caused significant tumor regression in mice. These results make MSH-PE38KDEL a potential candidate for further development as an anticancer drug for MSH-expressing tumors.

Acknowledgements: We would like to thank Li Yang and Ning Ma for their technical assistance, Fu Bo and Baihui Zhi for their assistance with animal care and management. 


\section{References}

[1] YANG L, WU XH, CHENG X. Current management of patients with primary melanoma of the vagina and literature review. China Oncology 2012; 22(6): 474-480.

[2] LANG PG. Current concepts in the management of patients with melanoma. Am J Clin Dermatol 2002; 3(6): 401-426. http://dx.doi.org/10.2165/00128071-200203060-00004

[3] AVRIL MF, AAMDAL S, GROB JJ, HAUSCHILD A, MOHR $\mathrm{P}$ et al. Fotemustine comparedwith dacarbazine in patients with disseminated malignantmelanoma: a phase III study. J Clin Oncol 2004; 22(6): 1118-1125. http://dx.doi.org/10.1200/ JCO.2004.04.165

[4] SPIETH K, KAUFMANN R, DUMMER R, GARBE C, BECKER JC et al. Temozolomide plus pegylated interferon alfa- $2 \mathrm{~b}$ as first-line treatment for stage IV melanoma: a multicenter phase II trial of the Dermatologic Cooperative Oncology Group (DeCOG). Ann Oncol 2008; 19: 801-806. http://dx.doi. org/10.1093/annonc/mdm565

[5] GARBE C, RADNY P, LINSE R, DUMMER R, GUTZMER $\mathrm{R}$ et al. Adjuvant low-dose interferona-2a with or without dacarbazine compared with surgery alone: a prospectiverandomized phase III DeCOG trial in melanoma patients with regional lymph node metastasis. Ann Oncol 2008; 19: 1195-1201. http://dx.doi.org/10.1093/annonc/mdn001

[6] HAUSCHILD A, WEICHENTHAL M, RASS K, LINSE $\mathrm{R}, \mathrm{BERKING} \mathrm{C}$ et al. Efficacy of low-dose interferon-alpha 2 a 18 versus 60 months of treatment in patients with primary melanoma of $\geq 1.5 \mathrm{~mm}$ tumor thickness: results of a randomized phase III DeCOG trial. J Clin Oncol 2010; 28: 841-846. http://dx.doi.org/10.1200/JCO.2009.23.1704

[7] EGGERMONT AM, SUCIU S, SANTINAMI M, TESTORI A, KRUIT WH et al. Adjuvant therapy with pegylated interferon alfa- $2 \mathrm{~b}$ versus observation alone in resected stage III melanoma: final results of EORTC 18991, a randomized phase III trial. Lancet 2008; 372: 117-126. http://dx.doi.org/10.1016/ S0140-6736(08)61033-8

[8] SLOMINSKI A, WORTSMAN J, LUGER T, PAUS R, SOLOMON S. Corticotropin releasing hormone and proopiomelanocortin involvement in the cutaneous response to stress. Physiol Rev 2000; 80: 979-981.

[9] SWOPE VB, MEDRANO EE, SMALARA D, ABDEL-MALEK ZA. Long-term Proliferation of human melanocytes is supported by the physiologic mitogens alpha-melanotropin, endothelir-1, and basic fibroblast growth factor. Exp Cell Res 1995; 217: 453. http://dx.doi.org/10.1006/excr.1995.1109

[10] NEWTON RA, SMIT SE, BARNES CC, PEDLEY J, PARSONS PG et al. Activation of the cAMP pathway by variant human MC1R alleles expressed in HEK and in melanoma cells. Peptides 2005; 26: 1818-1824. http://dx.doi.org/10.1016/ j.peptides.2004.11.031
[11] FROIDEVAUX S, CALAME-CHRISTE M, TANNER H, SUMANOVSKI L, EBERLE AN. A novel DOTA-alphamelanocyte-stimulating hormone analog for metastatic melanoma diagnosis. J Nucl Med 2002; 43: 1699-706.

[12] GALORE-HASKEL G, AZIZI E, MOHAMDI H, SCOPE A, CHAUDRU V et al. MC1R variant alleles and malignant melanoma risk in Israel. Eur J Cancer 2009; 45: 2015-2022. http://dx.doi.org/10.1016/j.ejca.2009.02.001

[13] TSATMALI M, ANCANS J, THODY AJ. Melanocyte function and its control by melanocortin peptides. J Histochem Cytochem 2002; 50: 125. http://dx.doi.org/ $\underline{10.1177 / 002215540205000201}$

[14] DURIE BG. Role of new treatment approaches in defining treatment goals in multiple myeloma - the ultimate goal is extended survival. Cancer Treat Rev 2010; 36: S18-S23. http://dx.doi.org/10.1016/S0305-7372(10)70008-6

[15] PASTAN I. Immunotoxins containing Pseudomonas exotoxin A: a short history. Cancer Immunol Immunother 2003; 52: 338-341.

[16] WOLF P, ELSASSER-BEILE U. Pseudomonas exotoxin A: From virulence factor to anti-cancer agent. Int J Med Microbiol 2009; 299: 161-176. http://dx.doi.org/10.1016/ j.ijmm.2008.08.003

[17] PASTAN I I, KREITMAN RJ. Immuotoxins for targeted cancer therapy. Adv Drug Deliv Rev 1998 Apr 6; 31(1-2): 53-88. http://dx.doi.org/10.1016/S0169-409X(97)00094-X

[18] HASSAN R, LERNER MR, BENBROOK D, LIGHTFOOT SA, BRACKETT DJ et al. Antitumor activity of SS(dsFv)PE38 and SS1(dsFv)PE38, recombinant antimesothelin immunotoxins against human gynecologic cancers grown in organotypic culture in vitro. Clin Cancer Res 2002; 22: 3520-3526.

[19] RAND RW, KREITMAN RJ, PATRONAS N, VARRICCHIO F, PASTAN I et al. Intratumoral administration of recombinant circularly permuted interleukin-4-pseudomonas exotoxin in patients with high-grade glioma. Clin Cancer Rer 2000; 6: 2157-2165.

[20] GROTE A, HILLER K, SCHEER M, MUNCH R, NORTEMANN B et al. A novel tool to adapt codon usage of a target gene to its potential expression host. Nucleic Acids Res 2005; 33: W526-531. http://dx.doi.org/10.1093/nar/gki376

[21] MALICH G, MARKOVIC B, WINDER C. The sensitivity and specificity of the MTS tetrazolium assay for detecting the in vitro cytotoxicity of 20 chemicals using human cell lines. Toxicology1997; 124: 179-192. http://dx.doi.org/10.1016/ S0300-483X(97)00151-0

[22] NIU QX, ZHOU YC, XU YX. Intradermal Model of B1 6 Melanoma in Mice .Carcinogenesis, Teratogenesis \& Mutagenesis 2009; 21: 0238-0240.

[23] XU HJ, ZHU DD. Experimental Study on Construction of Recombinant toxin MSH-PE40 and its antitumor activity. Chin J Lab Diagn 2005; 119: 680-682. 